Review

\title{
Coproducts of algae and yeast-derived single cell oils: A critical review of their role in improving biorefinery sustainability
}

\author{
Sophie Parsons ${ }^{\mathrm{a}, *}$, Michael J. Allen ${ }^{\mathrm{b}, \mathrm{c}}$, Christopher J. Chuck ${ }^{\mathrm{d}}$ \\ ${ }^{a}$ Department of Mechanical Engineering, University of Bath, Claverton Down, Bath BA2 7AY, UK \\ b Plymouth Marine Laboratory, Prospect Place, The Hoe, Plymouth PL1 3DH, UK \\ ${ }^{\mathrm{c}}$ College of Life and Environmental Sciences, University of Exeter, Exeter, Devon EX4 4QD, UK \\ ${ }^{\mathrm{d}}$ Department of Chemical Engineering, University of Bath, Claverton Down, Bath BA2 7AY, UK
}

\section{A R T I C L E I N F O}

\section{Keywords:}

Single cell oils

Bio-based products

Biorefineries

Techno-economic analysis

Life cycle assessment

\begin{abstract}
A B S T R A C T
Oleaginous microalgae and yeast are of increasing interest as a renewable resource for single cell oils (SCOs). These have applications in fuels, feed and food products. In order to become cost competitive with existing terrestrial oils, a biorefinery approach is often taken where several product streams are valorised alongside the SCO. Whilst many life cycle assessment (LCA) and Techno-economic (TEA) studies have employed this biorefinery approach to SCO production, a systematic analysis of their implications is missing. This review evaluates the economic and environmental impacts associated with the use of coproducts. Overall, protein production plays the greatest role in determining viability, with coproduct strategy crucial to considering in the early stages of research and development.
\end{abstract}

\section{Introduction}

Oleaginous microbes such as microalgae and yeast are increasingly considered as an important source of glyceride oils, termed single cell oils (SCO), for food and as a feedstock for biofuels and other industrial applications. These microorganisms can accumulate high levels of lipid within the cell, typically around $40 \%$ of the dry cell weight, though accumulation of up to $70-80 \%$ has previously been reported (Cohen and Ratledge, 2010; Ratledge, 1989). As deforestation and biodiversity impacts associated with palm and soybean cultivation continue, there is growing interest in the potential for SCOs, with their tuneable lipid profile, to act as a replacement for these lower value edible oils.

Whilst SCOs offer a technical replacement for many terrestrial oil applications, technology scale-up and commercialisation remains challenging especially when considering the low price of palm oil (\$680 $\mathrm{t}^{-1} 5$-year average (Indexmundi, 2019b). For phototrophic microalgal lipids, economic cost estimates vary between $\$ 1.64-\$ 30 \mathrm{Gal}^{-1}$ (\$0.43-\$7.90 $\mathrm{L}^{-1}$ or roughly between $\$ 0.4-\$ 7 \mathrm{~kg}^{-1}$ ), and climate change impact ranges in value from -75 to $534 \mathrm{~g} \mathrm{CO}^{\mathrm{eq}} \mathrm{MJ}^{-1}$ depending on the lipid productivity $\left(\mathrm{m}^{3} \mathrm{ha}^{-1} \mathrm{yr}^{-1}\right.$ ) assumed (Quinn and Davis, 2015). For heterotrophic fermentation, lipid cost ranges from $\$ 1.8 \mathrm{~kg}^{-1}$ to more than $\$ 10 \mathrm{~kg}^{-1}$ (Braunwald et al., 2016; Koutinas et al., 2014; Parsons et al., 2018a), and climate change impact from 30 to $71 \mathrm{~g} \mathrm{CO}_{2}$ eq $\mathrm{MJ}^{-1}$ (Chang et al., 2015; Karlsson et al., 2016). This can be compared with a climate change impact of $\sim 40 \mathrm{~g} \mathrm{CO}_{2} \mathrm{eq} \mathrm{MJ}^{-1}$ for refined palm oil (Pehnelt and Vietze, 2013).

In order to ensure economic viability and maximise environmental performance, a biorefinery approach where several co-products are produced alongside SCOs has been suggested (Chew et al., 2017; da Silva et al., 2014; Jin et al., 2015). Oleaginous algae and yeast processes have tremendous potential to benefit from this strategy, given that they are a platform for a number of different intra- and extra cellular products aside from lipids (Fig. 1). These include bulk proteins, recombinant proteins, amino acids (AA), carbohydrates, carotenoids, as well as fragrance chemicals, alcohols, and energy products. Several authors have evaluated coproduct options for SCO production processes (Chew et al., 2017; da Silva et al., 2014), but so far a critical review and analysis of the economic benefit and overall sustainability is missing. As such, this paper assesses potential coproducts to bulk SCO production (where application of main SCO product is in fuel, food, or feed production, rather than higher value niche application), before analysing the environmental and economic implications of these biorefinery approaches and their implications for sustainable process design in depth.

\footnotetext{
* Corresponding author.

E-mail address: s.c.parsons@bath.ac.uk (S. Parsons).
} 

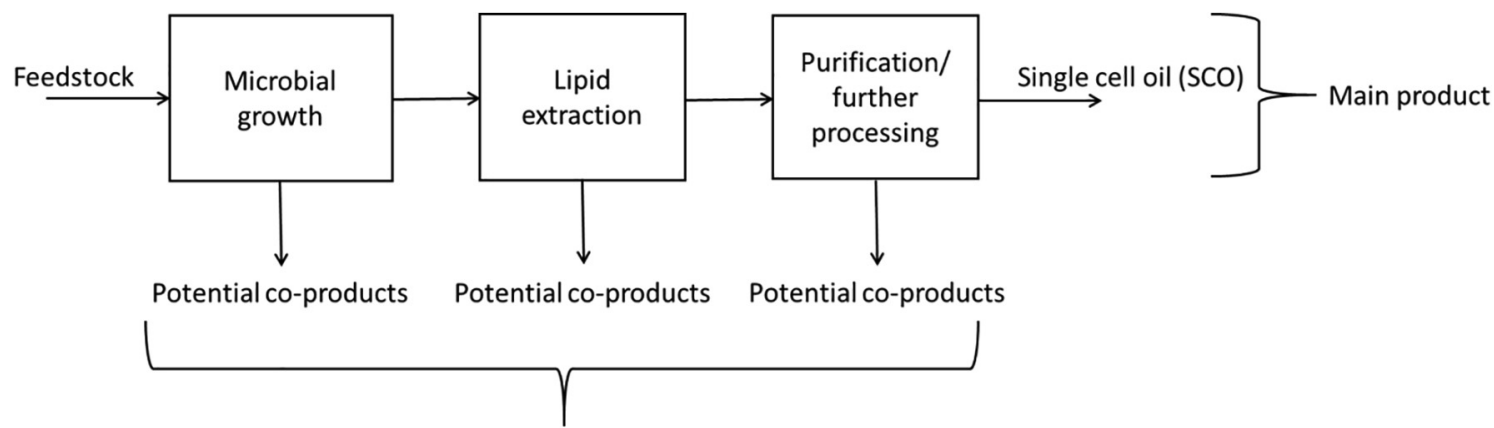

Opportunities to obtain additional value and substitute on-site energy and nutrients requirements

Fig. 1. Points in the Single Cell Oil (SCO) production process where co-product streams could be valorised.

\section{Co-products produced alongside single cell oils}

\subsection{Energy co-products}

Once the lipids have been extracted, the whole defatted algal or yeast biomass can be used in energy conversion these include: gasification, anaerobic digestion, fermentation, direct thermochemical conversion and combustion for electricity. This gives rise to a range of fuels including biogas, liquid transportation fuels, kerosene, ethanol, aviation fuel, and hydrogen. However, energy coproducts, particularly conversion for on-site energy production again require additional unit processes that often increases capital costs such that other valorisation routes may have better economic viability (Batan et al., 2016).

\subsection{Co-production of protein}

For bulk products where often minimal further processing is assumed, the remaining yeast/algae biomass after lipid extraction is usually modelled to enter markets for animal or fish feed. Single cell proteins for fish feed can even command a higher price than the terrestrial oils the main SCO product would be displacing ( $\$ 1300-\$ 1900$ tonne $\mathrm{e}^{-1}$ (1st grade fish meal at $65 \%$ protein content over past 10 -year period) (Indexmundi, 2019a). However, the nutritive requirements of fish tend to be less flexible than that of land animals (Seafish, 2016), and a required lipid content of $\sim 20 \%$ means oils like canola oil must be added to yeast biomasses (Batan et al., 2016). In addition further processing steps are required before the formulation is suitable for use as a feed product (Ritala et al., 2017). Microbial protein has been demonstrated in feed trials with terrestrial animals (Øverland et al., 2010); however, the low cost and well-established use of soybean meal has been a barrier to the adoption of single cell proteins in animal feed (Matassa et al., 2016). Yeast protein for human consumption obviously commands a higher price than that of animal feed. Most notably as mycoprotein, the amino acids and digestibility is similar to that of egg and milk. For microalgae, the protein content is highly variable but generally compares well to egg or soy protein, though cell wall digestibility is an issue (Matassa et al., 2016).

Two of the key aspects that effect the product value of protein, are the amino acid composition and digestibility. While the protein content and composition varies over time and with growing conditions, most yeasts, including oleaginous yeasts, have a remarkably similar AA composition (Martini et al., 1979). The main suggested use for a yeast protein co-product in the literature tends to be for animal nutrition. For this application, lysine, threonine, tryptophan, valine and isoleucine are all very important. In general yeast proteins have a well-balanced composition, including an elevated amount of lysine. This is very similar to soybean meal, and could potentially be used as a direct replacement in animal feed, to increase lysine levels of alternative protein sources (Michalik et al., 2014). This gives a useful guide on the potential value of the excess protein source.

Additionally, digestibility is also extremely important for animal nutrition. This has been looked at in less detail, however seemingly there is a large variation across species with $\mathrm{S}$. cerevisiae for example, being reasonably easy to break down while the oleaginous yeast Metschnikowia pulcherrima, despite having elevated levels of histine, lysine and methione compared with Soy protein had a very low peptin digestibity (50\%). This aspect could affect the price substantially, requiring a lysing or enzymatic treatment to increase bioavailability (Abeln, 2019).

Interestingly, in almost all TEA and LCA studies the additional unit processes needed for bulk protein extraction, purification and reformulation are often not taken into account (Batan et al., 2016; Gnansounou and Raman, 2016; Kern et al., 2017), although some implications of this have been explored by Manganaro et al. (2015). This gives a skewed assessment of the suitability of microbial proteins to enter existing protein markets.

\subsection{Co-production of glycerol and organic acids, typically commanding a market price of $<\$ 5 \mathrm{~kg}^{-1}$ )}

Glycerol is a by-product of fatty acid synthesis and biodiesel production, with this fraction obtained from the esterification of the SCO, it also often includes higher value pigments alongside the free fatty acids, methanol and fatty methyl esters. Glycerol is a low priced bulk commodity chemical, but its purification for use in the cosmetics or pharmaceutical industry can be prohibitively expensive (Rodrigues et al., 2017).

For this reason, many researchers have focused on developing ways to valorise crude glycerol which would be a side product of ester production of SCOs. Kitcha and Cheirsilp (2011) demonstrated the growth of different yeast strains on crude glycerol, determining the optimal crude glycerol content for optimal lipid productivity to be $10 \%$, with $0.5 \%$ ammonium sulfate giving a $\mathrm{C} / \mathrm{N}$ ratio of 17 (Kitcha and Cheirsilp, 2011). Recently Dobrowolski et al. (2019) demonstrated using crude glycerol and seawater to grow Yarrowia lipolytica as a low cost method for SCO production (Dobrowolski et al., 2019). Therefore, glycerol would probably be best utilised supplementing the primary carbon source in the initial SCO production, rather than being seen as a valuable co-product in its own right. Other uses for non-refined glycerol include anaerobic digestion, a supplement to animal feed, as a feedstock in the biological carboxylate platform to produce medium chain fatty acids and for thermochemical conversion (Rodrigues et al., 2017; Dams et al., 2018).

Extracellular production of organic acids, succinic, malic, oxalic and citric acid, has been demonstrated from oleaginous yeasts (Gao et al., 2016; Papanikolaou et al., 2006; Souza et al., 2014; Vlysidis et al., 2011). Succinic acid production has been demonstrated as part of a biorefinery concept, using glycerol waste from microbial biodiesel 
production in a further fermentation step to the organic acid (Vlysidis et al., 2011). Co-production of oxalic acid and SCOs at up to $21.5 \mathrm{~g}^{-1}$ (oxalic acid), and $3.5 \mathrm{~g} \mathrm{l}^{-1}$ (lipid) using Aspergillus niger strains on glycerol has been demonstrated (André et al., 2010), with maximum quantities of oxalic acid occurring in the late stationary phase, corresponding to the phase in which intracellular lipid turnover occurs (André et al., 2010; Papanikolaou et al., 2011). Strains of Y. lipolytica have been shown to simultaneously produce SCOs and citric acid or polyols (Filippousi et al., 2019; Makri et al., 2010; Papanikolaou et al., 2017). Growth using glycerol as the carbon source under nitrogen limited conditions sees sequential production of SCO and extracellular citric acid or polyols. Again, the period of intracellular lipid turnover coincides with secretion of these products into the culture medium (Filippousi et al., 2019; Makri et al., 2010; Papanikolaou et al., 2017). This is in contrast with other observations where production of lipid and citric acid or polyols occur across the whole fermentation time, showing a similar concentration trend to each other and without subsequent lipid break down occurring (Dobrowolski et al., 2016; Mirończuk et al., 2013). Succinic, fumaric and malic acids could replace fossil-derived commodity chemical maleic anhydride (Sauer et al., 2008), and succinic acid has been demonstrated in the manufacture of tetrahydrofuran and novel biopolymers such as bio-nylon. Succinic acid can also be used as a surfactant, detergent or foaming agent, as an ion chelator, and in the food industry. This wide range of applications means the anticipated market volume for succinic acid is estimated at easily above 270,000 tonnes (Sauer et al., 2008), with potential markets in the millions of tonnes for the bulk biopolymers.

\subsection{Co-production of carotenoids and other high value chemicals, commanding a market price of $>\$ 5 \mathrm{~kg}^{-1}$}

Higher value coproducts of bulk single cell oils include carotenoids, fragrance chemicals, pigments, omega- 3 and omega- 6 fatty acids, other PUFAs, and recombinant proteins. The global market for algal omega-3 fatty acids is expected to reach $\$ 1.2$ billion by 2024 . The market is highly fragmented with a number of small and domestic players (PR Newswire, 2019). The market for highly concentrated omega-3 fatty acids from fish oil is split into two major areas: nutraceuticals for human consumption, and as an ingredient in animal feed production. The cost price for PUFAs from algae has been estimated to lie between $\$ 500-\$ 1650$ per kg based on the existing PUFA market price range (van der Voort et al., 2017), with analysis estimating this could range from between $\$ 500-\$ 4290$ per $\mathrm{kg}$ depending on where in Europe production facilities are based. In contrast, fish oil (with a content of around $20 \%$ DHA/ EPA) costs around $\$ 2000$ per tonne and fish meal ( $~ 8 \%$ DHA/ EPA) around $\$ 1500$ per tonne, and therefore offer a far more cost-effective source of omega 3 fatty acids. The irony is, all-natural marine derived oils come from algae originally and are merely bio-accumulated in fish. Yet the use of algae directly as an omega-3 production platform (cutting out the 'middle fish') means products can be sold as vegan or vegetarian (with associated premium price), and it also reduces the pressure on stocks of small fish such as anchovies, herring and mackerel.

This is particularly important given increasing emphasis on sustainable harvest from regulatory bodies (De Silva and Turchini, 2008), Perhaps more importantly, safety concerns associated with methylmercury and organochlorine contaminants, also found bio-accumulated in seafood have contributed to a predicted growth in the algae omega-3 market at a CAGR of 11.3\% between 2019 and 2024 (PR Newswire, 2019).

However, some notable challenges faced producing algal omega-3s is that fish oil already has a mature production chain, and work is still needed to optimise many of the unit processes in order for them to become cost competitive with existing PUFA sources. Difficulty patenting, and extensive authorisation procedures and regulation are also cited as challenges in phototrophic production of algal omega-3s.
Nevertheless, following the failure to achieve economical and scalable production of microalgal derived biofuels, omega 3 production has emerged as the favoured sole primary product in many now-adapted business models, rather than as a biorefinery coproduct to aid process economics. The unwritten challenge from astute investors is generally for production costs below $\$ 5000$ per tonne of microalgae (typically $30 \%$ PUFA). Yet, the risks associated with increasing competition and increasing availability may lead to a further reduction in the market price for omega-3s and PUFAs (van der Voort et al., 2017), particularly if biorefinery models are deployed in earnest. In addition, the simple technical challenge of recovering the PUFA fatty acids that are also bound to the glyceride backbone and somehow leaving behind a bulk SCO to displace edible oils, mean that the two products appear mutually exclusive.

Carotenoids are terpenoid pigments with a wide range of applications; as a nutraceutical and cosmetic for human consumption, and as a nutrient and palatability improver in animal feed. Of the microbial carotenoids (astaxanthin, beta-carotene, lutein, lycopene, canthaxanthin, and zeaxanthin) astaxanthin has the largest market share followed by beta-carotene and lutein. However, market estimations for carotenoids vary dramatically in terms of share and size (Barreiro and Barredo, 2018). Despite substantial pharmaceutical interest in the more complex triterpenoids and their derivatives, these compounds are often found in such low amounts and in complex mixtures of related compounds, that large scale extraction is often technically difficult and prohibitively expensive.

Astaxanthin is used as a feed additive in aquaculture, poultry farming, and egg production and, alongside omega 3, has been the main target following the demise of the algal biofuels industry. Yet, roughly $95 \%$ of astaxanthin is produced synthetically rather than via a microbial route (Barreiro and Barredo, 2018) and the economic viability of many flagship algae based producers is uncertain. For co-production of SCOs with carotenoids, the $\mathrm{C} / \mathrm{N}$ ratio is one of the biggest factors affecting lipid and carotenoid production in yeast. Optimal ratios for each product can be at odds with one another, and are often down to the particular strain used (da Silva et al., 2014). TEA to date has focused on production of the carotenoid alone or alongside a fertiliser/feed product, as opposed to combined production with SCOs or biodiesel (Panis and Carreon, 2016; Thomassen et al., 2016), and again the extraction of the carotenoids from the SCO where they are solubilised is extremely challenging. Despite the relatively high value of carotenoid products ( $\beta$ carotene powders retail in the $\$ 100$ s per $\mathrm{kg}$ range), the market for carotenoids is small, with $\beta$-carotene and astaxanthin production volumes roughly 1200 tonnes per year and 300 tonnes per year respectively (Spolaore et al., 2006). This means that any large scale production would saturate the market rapidly and reduce the market price substantially (Richardson et al., 2012; Thomassen et al., 2016).

The same issue applies for fragrance and flavour chemicals. For example, de-novo Vanillin production has been demonstrated in Schizosaccharomyces pombe and Saccharomyces cerevisiae at 65 and $45 \mathrm{mg} \mathrm{l}^{-1}$ (Hansen et al., 2008), similarly $\gamma$-decalactone production by $Y$. lipolytica has been reported at $6.8 \mathrm{~g} \mathrm{l}^{-1}$ (Gomes et al., 2012), whereas 2-phenylethanol production of $14 \mathrm{~g} \mathrm{l}^{-1}$ has been reported from $M$. pulcherrima (Chantasuban et al., 2018). The market for each remains small - particularly for natural sources. It therefore follows that the coproduct market should be closely evaluated to ensure it does not become saturated (Richardson et al., 2012), or that there are alternative uses for the co-product that are larger and lower value that the coproduct can then enter when a reasonable production is obtained, and the high value market is saturated.

Another interesting and emerging co-product to SCO production are intracellular polysaccharides, such as $\beta$-D. glucans useful in medical applications. Co-production with SCOs is a research stream of increasing interest (Filippousi et al., 2019). Work evaluating the complex biochemical mechanisms in $Y$. lipolytica has shown that during the early oleaginous phase both lipid and polysaccharide biosynthesis occurs. 
After depletion of the carbon source, reserve lipids are used as an intracellular source of carbon. Where this relates to new cell mass production this was observed to be used to produce new lipid-free material like proteins and carbohydrates (Dourou et al., 2017).

\subsection{Previous studies into the feasibility of a microbial biorefinery}

One of the first feasibility studies in this area was carried out by Wijffels and Barbosa (2010). The authors identified potential revenue per tonne of phototrophic microalgal biomass as being $€ 1650$, based on: $€ 500$ from food protein, $€ 300$ from feed protein, $€ 150$ biofuels, $€ 200$ chemicals, €256 from supplying oxygen, $€ 140$ from nitrogen removal through waste water treatment, and $€ 100$ from fructans, glucans, and glycerol carbohydrates. This is based on a microalgal composition of $40 \%$ lipid, $50 \%$ protein and $10 \%$ carbohydrate. Lipids were assumed to be fractionated such that $25 \%$ entered a functional product market and the remaining $75 \%$ were used for biodiesel production. Proteins were separated by water solubility with a $20 \%$ soluble fraction entering the food market and $80 \%$ insoluble fraction entering the feed market. They concluded that without an integrated approach, microalgal biodiesel could never be produced economically (Wijffels and Barbosa, 2010). The rapid development of genetic modification tool kits for microalgae, as have been available in yeasts for decades, suggests that the production of new recombinant proteins in particular, as well as enhanced production of existing metabolites, may tip the balance towards economical production provided that suitable markets can be found for such protein material. Rather than as a simple source of protein building blocks, the bioactivation of the protein fraction (through for example growth promoters, antimicrobial activity, vaccines) offers intriguing possibilities.

However, not all exploitable products are accumulated under the same conditions or growth phase. In microalgae for example, early nitrogen depletion in the late exponential phase of batch culture is predominantly where proteins, starch and PUFAs are likely to be in greatest concentration, whereas triacylglyceride and carotenoids accumulate during late nitrogen depletion late stationary phase in most oleaginous microbes (Gifuni et al., 2019). This therefore leads to complexity when considering the overall culture strategy. For multiple product recovery a cascade approach is favoured, with extraction forming one of two strategies: either the maximum extraction of a single target product with the by-product going to low-value market; or multiproduct extraction with the recovery and sale of several medium value products. The first has a lower associated cost due to there being fewer unit operations, but the second has potential to obtain more economic value from a number of product streams. Which strategy to employ should be determined based on the outcome of market and techno-economic analysis to ensure that any additional processing costs could be mitigated by a real economic advantage (Gifuni et al., 2019). A breakdown of coproduct options for an SCO biorefinery is given in Fig. 2.

\section{The influence of co-products on the economic and environmental impact of single cell oils}

\subsection{Life cycle assessment and techno-economic analysis of biorefineries}

Integrated biorefineries present the ability to achieve overall reductions in environmental impact compared with incumbent (often fossil-derived) technology. This is due to the 'credit' received for coproducts, which can be energy, chemicals or materials.

Life cycle assessment is used as a way of quantifying energy consumption, emissions and overall environmental impact for a single cell oil production process. A summary of LCA and TEA studies which explicitly discuss the implications of co-products to the overall biorefinery system is given in Table 1. Ahlgren et al. (2015) identified six key challenges in the LCA of multi-product biorefinery systems. For example, functional unit selection can be difficult where several products are being produced in similar volumes. Aggregation of results (e.g. per 1 biorefinery) can be a way of overcoming this, but it is often an issue when making comparisons with other studies or communicating the results. Ultimately, functional unit should reflect the aims and objectives of the study. In most studies co-products from SCO production and their environmental impacts are accounted for through a system of allocation. This is typically handled in two ways: (i) through partitioning, whereby environmental impacts are allocated to particular co-products based on a particular attribute, this could be mass, energy content or volume, or an economic attribute such as market value; (ii) through system expansion, where the functional unit is defined in such a way that it reflects the function of all biorefinery products, or credit is given for the avoided burdens of each product which is substituted by producing each particular biorefinery product (Ahlgren et al., 2015). Allocation choice can have a significant effect on overall environmental impact - between expansion and partitioning, and between each of the different partitioning methods (Cherubini et al., 2011; Luo et al., 2009; Sandin et al., 2015). Ultimately, which allocation method is used should be dependent on the aims, objectives and decision-context of the LCA study itself (Sandin et al., 2015). For attributional studies where the physically dominant product is the focus of the functional unit then allocation method is less important. However, where the main product is not physically dominant (as is the case in SCO processes) then allocation method is vital on giving a good representation of the system. Of greatest significance in terms of overall results is allocation method when using system expansion with substitution in consequential studies (Ahlgren et al., 2015). It is therefore crucial that when carrying out LCAs for biorefinery processes that allocation is discussed and the method chosen for doing this clearly outlined. This is of particular importance given that LCA is increasingly used to demonstrate a biorefinieries ability to meet GHG reduction targets, and for biofuel processes this linked to policy requirements (European Parliament, 2018a; United States Environmental Protection Agency, 2019).

A distinction can be made between the co-production of energy or residual products (glycerin and animal feeds), and the intentional combining of biofuel production with that of higher value chemicals, which may require many further high energy unit processes in order to upgrade or purify. Co-production with higher value products may also affect the biofuel yield and other combined unit operations such as combined heat and power (CHP) and waste water treatment (Cai et al., 2018). This could all have an effect on the overall environmental impacts associated with the main biofuel product, with potential for coproducts with significant environmental impacts themselves to be overlooked depending on the method applied for allocation.

Cai et al. (2018) found, for example, that by diverting some intermediate sugars away from biochemical conversion to microbial biodiesel to the production of succinic acid this resulted in an increase of GHG emissions from 43 to $126 \mathrm{~g} \mathrm{CO}_{2} \mathrm{eq} \mathrm{MJ}^{-1}$ depending on what system-level allocation procedure was applied. The authors point to using aggregated biorefinery-level emissions results as opposed to product specific results as a way of better handling the integrated biorefinery analysis. This captures all emissions effects of the biorefinery, including emissions reduction benefits associated with co-products which might otherwise not be captured in a product-specific LCA fuel-focused regulation framework (Cai et al., 2018).

Another challenge in biorefinery LCA is dealing with land use change, which can be direct or indirect. Direct land use change relates to the land on which the feedstock is produced. Direct land use change is not included in LCA standards (ISO 14040 and ISO 14044) but it is included in the Renewable Energy Directive (European Parliament, 2018b). Indirect land use change relates to market-induced changes caused by feedstock production. Ultimately, direct land use change should be included in attributional LCA if land use change occurs from feedstock use, whereas the market analysis used to drive indirect land use change makes it closer to consequential LCA, but significant 


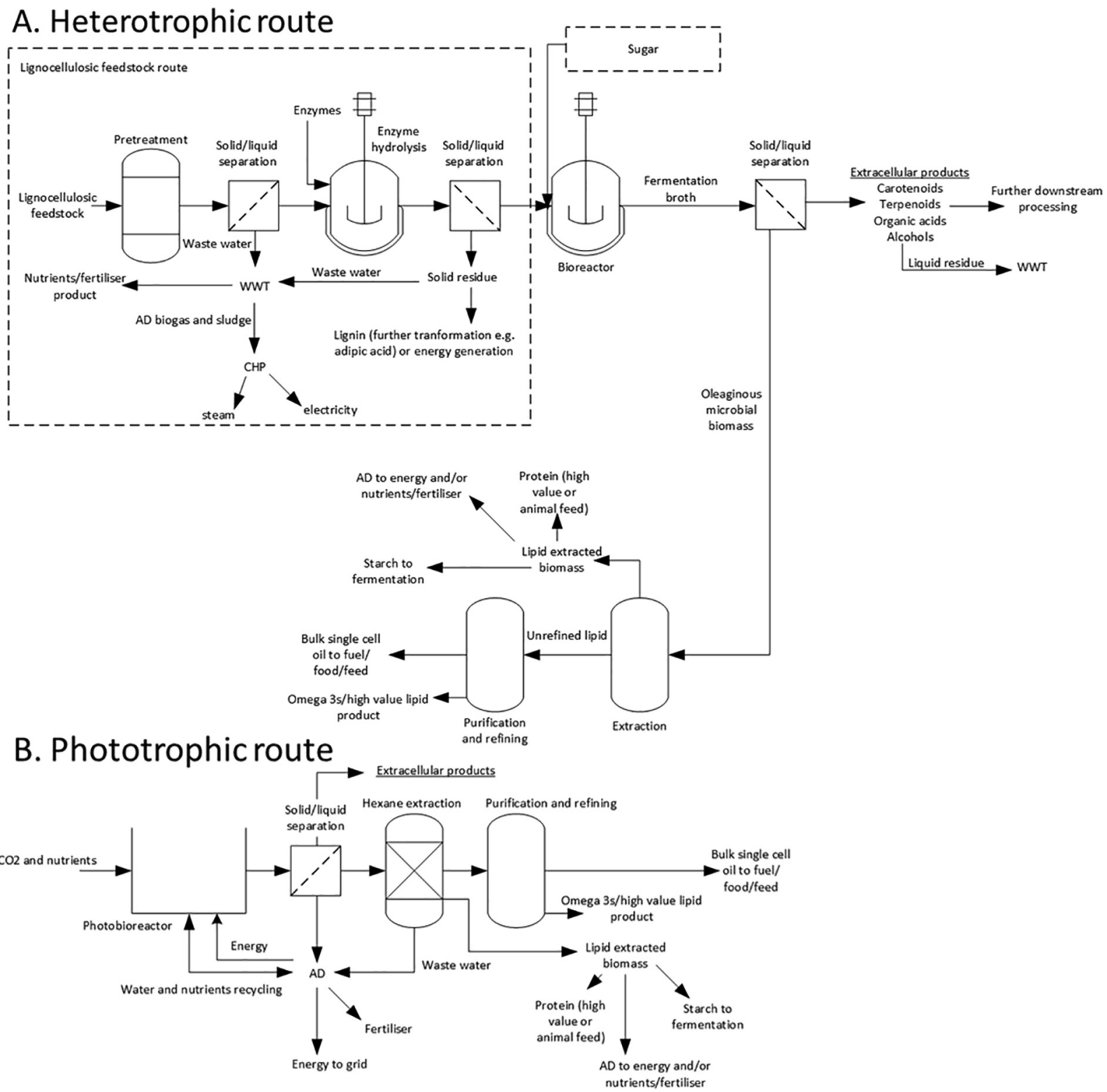

Fig. 2. Process flows for heterotrophic and phototrophic fermentation including potential co-product routes.

uncertainties still remain with its use as a metric for environmental impact (Ahlgren et al., 2015). Finally, an issue common to all biorefinery LCA modelling is accurately representing the timing of emissions - particularly in relation to biogenic carbon. The time difference between uptake and release of $\mathrm{CO}_{2}$ affects the overall climate benefits of biorefinery processes, as does the end treatment of biogenic waste (Ahlgren et al., 2015).

Microalgal and yeast biorefineries have a number of other LCA challenges which have been documented in reviews by several other authors (Collet et al., 2015; Parsons et al., 2018b; Quinn and Davis, 2015). These include the need for better coverage of environmental impact categories (many studies look solely at energy and GHG emissions), clarity on functional unit, more use of consequential LCA, clarity on algae/yeast composition, and greater support through experiments for any coproduct transformations (e.g. methane coproduction with biodiesel). Quinn and Davis (2015) cite variation in phototrophic microalgae productivity (lipid yield hectare ${ }^{-1}$ ) as a key metric dominating the variability in GHG emissions from microalgal biodiesel. They point to the importance of using experimentally validated models in for productivity in LCA studies so as to build a realistic picture of environmental impact.

Techno-economic analysis (TEA) is often used alone or alongside LCA to assess SCO production processes. A crucial part of ensuring economic viability extends beyond lipid productivity, and requires methods for capital cost reduction and better utilisation and valorisation of algal/yeast components (Dong et al., 2016). However, introducing additional processing steps could have knock-on effects in terms of increasing capital and operating costs (Biddy et al., 2016). Unlike LCA, there is no standardised approach to conducting a TEA study. But as with LCA, assumptions made about co-products can heavily influence the main product from the biorefinery under investigation. Batan et al. (2016) found that the selling price for phototrophic algal biomass had a significant influence on the minimum selling price of algal biodiesel, meaning economic viability of algal biodiesel was directly dependent on the market for any co-products. These is particularly important given that the markets for coproducts from biorefinery processes are often poorly defined or of limited size. 


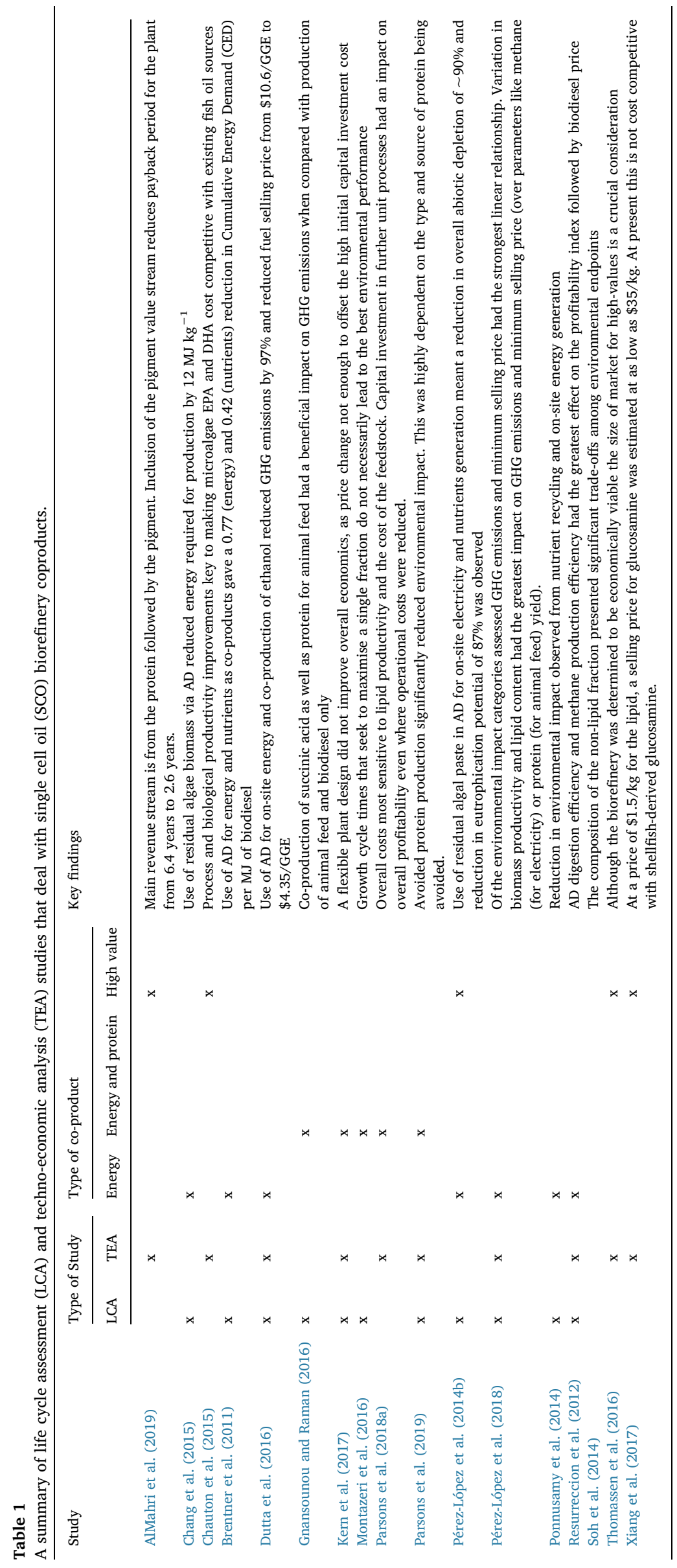




\subsection{Energy based co-products}

Collet et al. (2011) modelled the production of biogas, without coproducts, from the phototrophic cultivation of Chlorella vulgaris. Biogas was determined to be produced at $9385 \mathrm{~m}^{3} \mathrm{~d}^{-1}$, with a methane percentage of $70 \%$, after upgrading this account for $5062 \mathrm{~m}^{3} \mathrm{~d}^{-1}$ at $96 \%$ methane. The AD plant was modelled to consume $17,000 \mathrm{kWh} \mathrm{d}^{-1}$ of to produce heat, and $2694 \mathrm{kWh} \mathrm{d}^{-1}$ for electricity. Overall, the AD process equated to $21 \%$ of total electricity consumption. Building on this study, Ponnusamy et al. (2014) used this data to build a LCA model for a microalgal biodiesel biorefinery where the residual algal biomass enters an anaerobic digester and biogas is produced alongside the main biodiesel product. The main energy costs for processing the defatted algal biomass were associated with mixer and centrifuge electricity consumption. With part of the biogas used in the $\mathrm{AD}$ process, overall energy demand for $\mathrm{AD}$ was $1.2 \mathrm{MJ} \mathrm{kg}{ }^{-1}$ biodiesel produced. The overall total energy demand was therefore reduced from $58 \mathrm{MJ} \mathrm{kg}^{-1}$ to $46 \mathrm{MJ} \mathrm{kg}{ }^{-1}$ based on credits for co-product energy production being taken into account (Ponnusamy et al., 2014). Brentner et al. (2011) also observed a $60 \%$ reduction in direct energy use through $\mathrm{AD}$ to onsite CHP. Collet et al. (2011) coupled direct combustion and AD (to bioelectricity) to biodiesel production. Based on vehicle kilometres travelled, the algal biodiesel and bioelectricity scenario contained the highest energy demand (when compared with a terrestrial oil biorefinery and algal bioelectricity production only). GHG emissions were much lower than the terrestrial comparator but higher than producing only algal bioelectricity.

Resurreccion et al. (2012), building on this work, reasoned that given more energy is required to drive the same distance on biodiesel than bioelectricity, the production of electricity from $\mathrm{AD}$ is a more efficient way of producing energy and sequestering GHGs than biodiesel production. Within multi energy product phototrophic algal biorefineries, allocation based on energy content and subsequent environmental impact assigned to biodiesel can vary largely depending on how algae residue is handled (Resurreccion et al., 2012). For example, Collet et al. (2014) allocated $51 \%$ of total environmental impact to algae residue and glycerine. Whereas, Passell et al. (2013) allocated 58\% to hydrocarbons and algae residue at the crude algae oil stage but overall energy allocation ratio is $90 \%$ to biodiesel and $10 \%$ to glycerine (Passell et al., 2013).

Alternatively, Chang et al. (2015) investigated heterotrophic Thraustochytrids production of biodiesel coupled with production of biogas which was solely used to produce process energy. Overall, using residual algae biomass in $\mathrm{AD}$ reduced energy required for production by $12 \mathrm{MJ} \mathrm{kg}^{-1}$. Dutta et al. (2016) examine the LCA and techno-economic case for including AD for onsite energy and ethanol co-production in algal biodiesel production. They contrasted algal biodiesel production in Portugal with the NREL algal biodiesel modelling. Where process design includes $\mathrm{AD}$ and ethanol production (NREL case) GHG emissions were reduced from $162 \mathrm{~kg} \mathrm{CO}_{2}$ eq/GGE to $5.3 \mathrm{~kg} \mathrm{CO} 2$ eq/GGE, and minimum fuel selling price reduced from $\$ 10.6 / \mathrm{GGE}$ to $\$ 4.35 / \mathrm{GGE}$ (Dutta et al., 2016).

\subsection{Protein and energy}

The majority of LCA and TEA studies in this area have evaluated the production of three products; biodiesel with an energy product and proteinous animal feed. Kern et al. (2017) integrated TEA and LCA into a deterministic optimisation framework to conduct a 'real options analysis' for a plant that could switch between selling algal meal for animal feed or use it to recover nutrients and generate energy onsite via $\mathrm{AD}$ and CHP. They found that under mean price conditions annual revenue from algal meal as animal feed (\$24 million) far outweighed the combined benefits of nutrient recovery and energy reduction ( $\$ 13$ million). Under current price dynamics the flexible plant did not improve NPV, as movement in price was not enough to offset the high initial capital cost of installing an AD plant and CHP.

From an LCA perspective, Global Warming Potential (GWP) decreased as the plant switched over towards on-site energy generation and nutrient recovery, but it also widened uncertainty around the value for GWP. This peaked at 50\% of simulations, with GWP continuing to fall but uncertainty narrowing as simulations tended towards full onsite energy generation. The modelling shows an interesting divergence between what are optimal LCA and optimal TEA conditions. This could be reconciled through government incentives linked to meeting particular GHG emissions criteria, making a switch to on-site generation more economically beneficial particularly if it was linked to favourable price conditions (when price of algal meal is low and electricity is high) (Kern et al., 2017). Pérez-López et al. (2018) used Monte Carlo analysis to consider uncertainty in LCA and TEA. Through evaluating Pearson's and Spearman's correlation coefficients, they found a strong correlation overall between GHG emissions and minimum selling price; however, this correlation was not as strong between other environmental impacts like eutrophication and selling price. Cumulative Energy Demand (CED) and minimum selling price were also not as well correlated as GHG emissions and minimum selling price. The authors suggest this may be due to co-product credits - where protein substitution leads to a reduction of between $0.5 \%$ and $42 \%$ of the production stage CED, but is only $15 \%$ of GHG emissions generated. Overall, variation in biomass and lipid productivity had the greatest effect on results across all impact categories, but for eutrophication, variation protein content, methane yield, and protein substitution ratio also influenced the final scores.

Methane yield variation also influenced CED. This analysis demonstrates the importance of carrying out uncertainty assessment, and demonstrated the significant environmental benefits co-products can bring (Pérez-López et al., 2018). Montazeri et al. (2016) also included both protein to animal feed and on-site energy generation and nutrient recovery. In addition to protein, enough biogas is produced to enable electricity generation of $17-100 \%$ total demand, and enough heat generated for $68-100 \%$ total demand. Onsite generation of energy accounted for 90\% co-product credits (avoided environmental impact) from CED, but only $20 \%$ from eutrophication. Avoided impact for eutrophication was dominated by soybean meal and avoided nutrients production (Montazeri et al., 2016).

Soratana et al. (2014) demonstrate the complexities associated with analysing the LCA of various co-product scenarios in an algal biodiesel biorefinery. They evaluated six different scenarios based on biodiesel coproducts composed of; bioethanol production from lipid extracted algal starch, biomethane production, application on land as a fertiliser, animal feed, nutrient recycling from $\mathrm{AD}$, and recycling of $\mathrm{CO}_{2}$ from simultaneous saccharification and fermentation (SSF). The best performing in terms of environmental impact included bioethanol production, $\mathrm{AD}$ with $\mathrm{CHP}$, land application of post $\mathrm{AD}$ solid digestate and nutrient recycling. The scenario which included bioethanol production and land application of solid residues from SSF did not score as well however, due to the lower $\mathrm{N}$ content compared with the $\mathrm{AD}$ solid digestate meaning less urea production was avoided. Sensitivity analysis showed significant parameters for environmental impact to be: energy consumed during centrifugation of fertiliser material from SSF, lipid content in the algae, $\mathrm{N}$-availability content, and \% yield of bioethanol. Despite the scenario with the most co-products having the overall lowest environmental impact across the scenarios, the authors point out that this isn't always the case as the scenario which included algal meal to animal feed only performed better than the scenario that included bioethanol production and SSF residue to fertiliser.

From an economic perspective higher income is achieved from greater quantities rather than greater types of co-product (Soratana et al., 2014). Soh et al. (2014) evaluated the relationship between lipid, protein, nutrients and starch productivity in terms of GHG emissions. They found there are important trade-offs that occur among processing choices of co-product fractions - such as the way in which nutrients are recovered or the type of energy that is produced (on-site via $\mathrm{AD}$ 
compared with starch fermentation to bioethanol). They concluded that algal biorefineries need not be optimised for lipid productivity, where low lipid producing species could be better suited for ethanol fermentation or use as an animal feed. Overall, the biorefinery should be considered as a whole system - where engineered increases in lipid productivity need to be balanced against the intended use of non-lipid fractions (Soh et al., 2014).

\subsection{Organic acids and high value products}

Manganaro et al. (2015) assessed the co-production of omega-3s, animal feed and a hydrotreated algal oil. Based on a facility producing hydrotreated algal oil at $153 \mathrm{Mgal} \mathrm{yr}^{-1}$, generating nutraceuticals at $0.05 \%$ of lipid yield represents $\sim 25 \%$ of global algal omega- 3 market from that one facility alone (animal feed production from this facility would be $1.4 \%$ of the US market). The study assumed a carbon reduction credit of $\$ 5 \mathrm{t}^{-1}$ was taken. In terms of upfront capital costs associated with nutraceutical production this was estimated to be $30 \%$ of the hydrotreater capital cost. Total digestible nutrients and crude protein was estimated to be $48 \%$ and $36 \%$ respectively for which a value of between $\$ 100$ and $\$ 225$ tonne $^{-1}$ could be obtained but that trace toxins or other elements outside of the range expected in animal feed could affect its price (Bryant et al., 2012). Overall, selling at $\$ 225 \mathrm{t}^{-1}$ reduced the sales price of hydrotreated oil by $\$ 3.24 \mathrm{Gal}^{-1}$.

For omega-3 production for human and animal consumption, toxic materials must be prevented from entering the supply chain. The practical effect of this means that all inputs including water supply and nutrients, including $\mathrm{CO}_{2}$ must be free of toxins (if for example, coming in as waste $\mathrm{CO}_{2}$ from an industrial facility). As such, the authors assumed a $\mathrm{CO}_{2}$ purification cost of $\$ 40$ tonne ${ }^{-1}$, with an average selling price for omega-3s of $\$ 30 \mathrm{lb}^{-1}$. In this study $60 \%$ of processing costs for omega- 3 oils were associated with recovery and purification steps. Interestingly, overall the nutraceutical production resulted in only a $\$ 0.14 /$ gal reduction in hydrotreated algal oil selling price, far lower than when the protein was valorised as a co-product (Manganaro et al., 2015).

In a similar LCA study Gnansounou and Raman (2016) evaluated phototrophic algal biodiesel with protein and succinic acid co-products, comparing environmental impact of oil and protein production with and without the succinic acid co-product. Overall, the study found the additional production of succinic acid, biodiesel and protein could be beneficial over production of biodiesel and protein only (Gnansounou and Raman, 2016).

In terms of higher value lipids, Chauton et al. (2015) looked at EPA and DHA production for aquafeed. In terms of cultivation method flat panel bioreactors were found to be the most effective in terms of production cost at \$39 per $\mathrm{kg}$ for EPA (eicosapentaenoic acid) and DHA (docosahexaenoic acid); however, if biological productivity were to increase and mixing energy decreased this could drop to $\$ 11.9$ per $\mathrm{kg}$ for EPA and DHA (Chauton et al., 2015).

Further studies have evaluated the production of astaxanthin only from microalgae (Dursun et al., 2018; Panis and Carreon, 2016). Panis and Carreon (2016) found that at a cost per kilogram of $\$ 1690-\$ 7400 \mathrm{~kg}^{-1}$, they were unable to compete with synthetic astaxanthin (Dursun et al., 2018) observed that powdered astaxanthin is more profitable than an astaxanthin oil mixture. Simiarly, Pérez-López et al., (2014a) and Thomassen et al. (2016) assessed carotenoid production. In these phototrophic cultures, a major contributor to environmental impact during production is reactor lighting, particularly in the stress stage of cultivation (Pérez-López et al., 2014a). Thomassen et al. (2016) observed the most profitable scenario to be where the medium is recycled and an open pond reactor is used, despite the photobioreactor decreasing culture medium costs. This is due to the higher initial capital investment associated with the photobioreactor (Thomassen et al., 2016). Pérez-López et al., (2014b) evaluated a mixture of bioactive compounds from microalgae through LCA. These included beta-carotene, alpha-tocopherol, chlorophyll, polyphenol and PUFAs. The algae residue was sent to $\mathrm{AD}$ and so led to avoided fertiliser and electricity production. Mass allocation was used for the co-products due to lack of market data on these compounds. Environmental impact was evaluated per $\mathrm{kg}$ of microalgae. PUFAs had the highest contribution to environmental impact given their higher mass yield than alphatocopherol or chlorophyll. Culturing (including development of the inoculum) contributed the highest amount to total environmental impact across all impact categories. This related particularly strongly to $\mathrm{N}$ source. The authors investigated the impact of $\mathrm{N}$ use through different scenarios finding that using the digestate as a $\mathrm{N}$ source was the worst performing from an environmental perspective against the other scenarios (aside from their base case scenario). This is because not all $\mathrm{N}$ is supplied by the digestate meaning sodium nitrate is still required. As such, the use of other $\mathrm{N}$ sources was found to be more environmentally preferable than using the digestate (Pérez-López et al., 2014b).

Parsons et al., (2018a) assessed the production of fragrance chemical 2-phenylethanol, alongside protein production from the oleaginous yeast $M$. pulcherrima. However, as the authors modelled a process that would produce 25,000 tonnes of yeast biomass a year, they assigned a value of $\$ 5.50 \mathrm{~kg}^{-1}$ to the 2-PE reasoning at this production scale it should be treated as a bulk chemical not a fragrance molecule. This is in line with the cost of $2 \mathrm{PE}$ produced from fossil resources as opposed to the naturally extracted fragrance molecule. In this scenario they found that lipid rather than co-product production had the greatest impact on process economics, yielding a minimum SCO selling price of $\$ 3850-\$ 8,580$ tonne $^{-1}$ dependent on feedstock and cultivation method. Using the same yeast species, they found that for cultivation on seaweed as a fermentation feedstock, economic and environmental impacts were dominated by the feedstock production, with higher value products having little influence on overall impact. Protein production did lead to significant avoided impacts but this was highly dependent on the type of protein being avoided (Parsons et al., 2018a, 2019).

AlMahri et al. (2019) evaluated the production of saponified fatty acids, protein and pigments. They found that producing pigments and fatty acids alongside the protein reduced the payback time of the plant from 6.38 years to 2.62 years (AlMahri et al., 2019). Xiang et al. (2017) evaluated the production of lipid and glucosamine from Cyclotella. They found the open pond system gave the best selling price for glucosamine compared with the photobioreactor $\left(\$ 35 \mathrm{~kg}^{-1}\right.$ and $\$ 82 \mathrm{~kg}^{-1}$ respectively). They found selling the lipids as a food, increasing the scale, and $\mathrm{AD}$ reduced the price to $\$ 28-31 \mathrm{~kg}^{-1}$ (Xiang et al., 2017).

\section{Implications for future SCO biorefinery design}

In the following section, four key design aspects for an oleaginous biorefinery are discussed, that are vital for the future development of this area.

\subsection{The protein fraction is as important as the lipid from an environmental and economic perspective}

Overall, protein is key to determining economic cost and environmental impact. Though the nature of this influence is dependent on the particular case under investigation. Kern et al. (2017) found that using protein as animal feed over on-site energy generation had a beneficial economic impact, as upfront capital cost of AD and CHP units was never fully recovered. However, from an environmental perspective on-site energy generation was beneficial over animal feed production, given the high amount of electricity and heat used at the facility (Kern et al., 2017). Pérez-López et al. (2018) found a strong correlation between GHG emissions and selling price for their case study, but CED and selling price had a less strong correlation due to variation in environmental coproduct credits due to protein substitution. Given the volume of protein produced at an industrial scale, application as an animal feed can be more profitable than producing higher value nutraceutical 
products (Manganaro et al., 2015). With the work reviewed here pointing to low to medium value applications $\left(<\$ 5 \mathrm{~kg}^{-1}\right)$ as the most environmentally and economically viable option. Here, understanding trade-off between cascading approaches is crucial - whether to focus on selectively recovering one target product, with the rest going to low value bulk applications, or to focus on several medium value products but incur higher downstream processing costs.

\subsection{High and low value product streams are simply not compatible}

Culture strategy and subsequent downstream approach is important for low to medium value co-products, particularly for energy source as residual biomass offers a number of different processing routes from directly combustion, to $\mathrm{AD}$ and CHP, to fermentation and ethanol production. Scenario analysis (such as that used by Soratana et al. (2014)) is an important tool in determining best options from an environmental and economic perspective.

Where high value applications are considered, ultimately this is incompatible with an industrial lipid product, as production volumes of expensive but niche co-products risk saturating the market. Co-product markets should be closely evaluated to ensure that this does not become the case (Richardson et al., 2012), but realistically this is a different type of biorefinery system from one producing single cell oils for food (bulk), feed or fuels. Specific requirements for market entry and uncertainties relating to achievable market price of products must be addressed.

One way of overcoming this is to use high value co-products for multiple markets. For example, in a small niche biorefinery, a co-product such as 2-phenylethanol could be sold into the fragrance and flavour markets while still on the small scale, however, when that biorefinery is scaled up to larger production the $2 \mathrm{PE}$ could be used as a bulk chemical feedstock as a novel route to bio-styrene or the octane improver ethylcyclohexane.

\subsection{Culture strategy and co-product downstream processing should be considered from the outset}

A wide range of minimum estimated selling prices and environmental impacts associated with the lipid product have been reported based on what and how co-product streams are utilised. Soratana et al. (2014) demonstrated how complex this can be, finding that having the most co-products does not always mean the lowest environmental impact, and environmental gains from fertiliser use were dependent on the quality and nitrogen content of the fertiliser (Soratana et al., 2014). Soh et al. (2014) made clear the trade-offs between lipid, protein, nutrients and starch productivity - highlighting the importance of considering the system as a whole. Currently, SCO process optimisation is based around improving the conditions for lipid productivity increase. This does not consider culture strategy, where different fermentation conditions are required for viable co-product synthesis. For an economically and environmentally viable biorefinery, focus must shift towards the whole system, where the algae or yeast species is a platform for protein, lipid, carbohydrate, and nutrients etc. with accessible models allowing researchers to assess the impact of their co-products and lipid yields on the overall selling price.

\subsection{Combined LCA, TEA, and uncertainty analysis can help to optimise use of coproducts}

The work reviewed within this paper demonstrates the important role that LCA, TEA, and uncertainty analysis plays in evaluating biorefinery design from the outset of the development process. They also play a key role in continuing assessment throughout research and development stages to pilot scale and beyond. In LCA, methodological challenges associated with allocation, functional unit and system boundary setting, and particular environmental impacts such as land use and biogenic carbon, require research - particularly given their policy implications. In the meantime, transparent and justified methodological choices supported by uncertainty assessment should be included within all attributional and consequential LCA biorefinery studies.

Uncertainty assessment has been demonstrated by authors to be valuable in terms of assessing co-product scenarios, as well as incorporating market price fluctuations into economic analysis. Sensitivity analysis, and in particular, global sensitivity analysis, can be used to determine which key input parameters have the most influence on environmental or economic impact. This is important, especially in early design stages, in order to determine key process parameter sensitivities and future development strategy. TEA and market analysis play a crucial role in understanding the economic feasibility relating to decision-making on coproducts and coproduct strategy. It is key to understanding whether or not the system could work on scale-up mitigating much greater risk further down the line. Related to this is the 'Collingridge Dilemma' - where in early stages of technology development the ability to control and alter process design is high, but level of understanding on the technology mean that uncertainty is also high (Collingridge, 1980). As with LCA, scenario analysis and sensitivity analysis are useful tools used to explore design options and their potential influence on the system as a whole.

\section{Conclusion}

The environmental and economic viability of SCOs can be improved by taking a biorefinery approach and valorising coproduct streams. Of the many coproduct options, the protein fraction appears to be central to determining minimum oil selling price and environmental impact. Determining biorefinery strategy is crucial early on, with high and low value product streams not compatible with each other due to the significant differences in product market size. Market analysis, TEA and LCA are useful tools for determining scale-up and production strategy though must be applied from the outset.

\section{CRediT authorship contribution statement}

Sophie Parsons: Conceptualization, Investigation, Writing - original draft. Michael J. Allen: Writing - review \& editing. Christopher J. Chuck: Writing - review \& editing.

\section{Declaration of Competing Interest}

The authors declare that they have no known competing financial interests or personal relationships that could have appeared to influence the work reported in this paper.

\section{Acknowledgements}

This research has been funded by the Industrial Biotechnology Catalyst (Innovate UK, BBSRC, EPSRC) to support the translation, development and commercialisation of innovative Industrial Biotechnology processes (EP/N013522/1), we would like to thank both Dr. Felix Abeln and Dr. Luca Longanesi for their insightful contribution into yeast composition.

\section{References}

Abeln, F., 2019. Advancing the industrial relevance of the oleginous yeast Metschnikowia pulcherrima. In: Chemical Engineering, Vol. PhD, University of Bath, pp. 234.

Ahlgren, S., Björklund, A., Ekman, A., Karlsson, H., Berlin, J., Börjesson, P., Ekvall, T., Finnveden, G., Janssen, M., Strid, I., 2015. Review of methodological choices in LCA of biorefinery systems - key issues and recommendations. Biofuels Bioprod. Biorefin. 9 (5), 606-619.

AlMahri, M.A., Jung, K., Alshehhi, M., Bastidas-Oyanedel, J.R., Schmidt, J.E., 2019. Techno-economic assessment of microalgae biorefinery as a source of proteins, 
pigments, and fatty acids: a case study for the United Arab Emirates. In: BastidasOyanedel, J.R., Schmidt, J. (Eds.), Biorefinery. Springer, pp. 679-693.

André, A., Diamantopoulou, P., Philippoussis, A., Sarris, D., Komaitis, M., Papanikolaou, S., 2010. Biotechnological conversions of bio-diesel derived waste glycerol into added-value compounds by higher fungi: production of biomass, single cell oil and oxalic acid. Ind. Crops Prod. 31 (2), 407-416.

Barreiro, C., Barredo, J., 2018. Carotenoids production: a healthy and profitable industry. In: Barreiro, C., Barredo, J. (Eds.), Microbial Carotenoids: Methods in Molecular Biology. Humana Press, New York, NY, pp. 45-55.

Batan, L.Y., Graff, G.D., Bradley, T.H., 2016. Techno-economic and Monte Carlo probabalistic analysis of microalgae biofuel production system. Bioresour. Technol. 219, 45-52.

Biddy, M.J., Davis, R., Humbird, D., Tao, L., Dowe, N., Guarnieri, M.T., Linger, J.G., Karp, E.M., Salvachúa, D., Vardon, D.R., Beckham, G.T., 2016. The techno-economic basis for coproduct manufacturing to enable hydrocarbon fuel production from lignocellulosic biomass. ACS Sust. Chem. Eng. 4 (6), 3196-3211.

Braunwald, T., French, W.T., Claupein, W., Graeff-Honninger, S., 2016. Economic assessment of biodiesel production using heterotrophic yeast. Int. J. Green Energy 13, 274-282.

Brentner, L.B., Eckelman, M.J., Zimmerman, J.B., 2011. Combinatorial life cycle assessment to inform process design of industrial production of algal biodiesel. Environ. Sci. Technol. 45 (7060-7070).

Bryant, H.L., Gogichaishvili, I., Anderson, D., Richardson, J.W., Sawyer, J., Wickersham, T., Drewery, M.L., 2012. The value of post-extracted algae residue. Algal Res. 1 (2), 185-193.

Cai, H., Han, J., Wang, M., Davis, R., Biddy, M., Tan, E., 2018. Life-cycle analysis of integrated biorefineries with co-production of biofuels and bio-based chemicals: coproduct handling methods and implications. Biofuels Bioprod. Biorefin. 12, 815-833.

Chang, K.J.L., Rye, L., Dunstan, G.A., Grant, T., Koutoulis, A., Nichols, P.D., Blachburn, S.L., 2015. Life cycle assessment: heterotrophic cultivation of thraustochytrids for biodiesel production. J. Appl. Phycol. 27, 639-647.

Chantasuban, T., Santomauro, F., Gore-Lloyd, D., Parsons, S., Henk, D., Scott, R.J., Chuck, C.J., 2018. Elevated production of the aromatic fragrance molecule, 2-phenylethanol, using Metschnikowia pulcherrima through both de novo and ex novo conversion in batch and continuous modes. Chem. Technol. Biotechnol.

Chauton, M.S., Reitan, K.I., Norsker, N.H., Tveterås, R., Kleivdal, H.T., 2015. A technoeconomic analysis of industrial production of marine microalgae as a source of EPA and DHA-rich raw material for aquafeed: research challenges and possibilities. Aquaculture 436 (20), 95-103.

Cherubini, F., Strømman, A.H., Ulgiati, S., 2011. Influence of allocation methods on the environmental performance of biorefinery products-a case study. Resour. Conserv. Recycl. 5 (11), 1070-1077.

Chew, K.W., Yap, J.Y., Show, P.L., Suan, N.H., Juan, J.C., Ling, T.C., Lee, D.-J., Chang, J.S., 2017. Microalgae biorefinery: high value products perspective. Bioresour. Technol. 229, 53-62.

Cohen, Z., Ratledge, C., 2010. Single Cell Oils - Microbial and Algal Oils. AOCS Press.

Collet, P., Helias, A., Lardon, L., Ras, M., Goy, R.-A., Steyer, J.P., 2011. Life cycle assessment of microalgae culture coupled to biogas production. Bioresour. Technol. 102, 207-214.

Collet, P., Helias, A., Lardon, L., Steyer, J.P., Bernard, O., 2015. Recommendations for life cycle assessment of algal fuels. Appl. Energy 154, 1089-1102.

Collet, P., Lardon, L., Hélias, A., Bricout, S., Lombaert-Valot, I., Perrier, B., Lépine, O., Steyer, J.P., Bernard, O., 2014. Biodiesel from microalgae - life cycle assessment and recommendations for potential improvements. Renew. Energy 71, 525-533.

Collingridge, D., 1980. The Social Control of Technology. Frances Pinter, University of Michigan.

da Silva, T., Gouveia, L., Reis, A., 2014. Integrated microbial processes for biofuels and high value-added products: the way to improve cost effectiveness of biofuel production. Appl. Microbiol. Biotechnol. 98 (3), 1043-1053.

Dams, R., Viana, M.B., Guilherme, A.A., Silva, C.M., dos Santos, A.B., Angenent, L.T., Santaella, S.T., Leitão, R.C., 2018. Production of medium-chain carboxylic acids by anaerobic fermentation of glycerol using a bioaugmented open culture. Biomass Bioenergy 118, 1-7.

De Silva, S., Turchini, G.M., 2008. Towards understanding the impacts of the pet food industry on world fish and seafood supplies. J. Agric. Environ. Ethics 21 (5), 459-467.

Dobrowolski, A., Drzymała, K., Rzechonek, D.A., Mituła, P., Mirończuk, A.M., 2019. Lipid production from waste materials in seawater-based medium by the yeast Yarrowia lipolytica. Front. Microbiol. 10 (547).

Dobrowolski, A., Mituła, P., Rymowicz, W., Mirończuk, A.M., 2016. Efficient conversion of crude glycerol from various industrial wastes into single cell oil by yeast Yarrowia lipolytica. Bioresour. Technol. 207, 237-243.

Dong, T., Knoshaug, E.P., Davis, R., Laurens, L.M.L., Van Wychen, S., Pienkos, P.T., Nagle, N., 2016. Combined algal processing: a novel integrated biorefinery process to produce algal biofuels and bioproducts. Algal Res. 19, 316-323.

Dourou, M., Mizerakis, P., Papanikolaou, S., Aggelis, G., 2017. Storage lipid and polysaccharide metabolism in Yarrowia lipolytica and Umbelopsis isabellina. Appl. Microbiol. Biotechnol. 101 (19), 7213-7226.

Dursun, D., Koulouris, A., Dalgıç, A.C., 2018. Process simulation and techno economic analysis of astaxanthin production from agro-industrial wastes. Waste Biomass Valorization.

Dutta, A., Neto, F., Coelho, M.C., 2016. Microalgae biofuels: a comparative study on techno-economic analysis \& life-cycle assessment. Algal Res. 20, 44-52.

European Parliament, 2018a. Directive (EU) 2018/2001 of the European Parliament and of the Council of 11 December 2018 on the promotion of the use of energy from renewable sources (recast). In: PE/48/2018/REV/1 (Ed.) E. Parliament.
European Parliament, 2018b. DIRECTIVE (EU) 2018/2001 of the European Parliament and of the Council of 11 December 2018 on the promotion of the use of energy from renewable sources (Text with EEA relevance.) (Ed.) E. Parliament.

Filippousi, R., Antoniou, D., Tryfinopoulou, P., Nisiotou, A.A., Nychas, G.-J., Koutinas, A.A., Papanikolaou, S., 2019. Isolation, identification and screening of yeasts towards their ability to assimilate biodiesel-derived crude glycerol: microbial production of polyols, endopolysaccharides and lipid. Appl. J. Microbiol. 127 (4), 1080-1100.

Gao, C., Yang, X., Wang, H., Rivero, C.P., Li, C., Cui, Z., Qi, Q., Lin, C.S.K., 2016. Robust succinic acid production from crude glycerol using engineered Yarrowia lipolytica. Biotechnol. Biofuels 9 (179).

Gifuni, I., Pollio, A., Safi, C., Marzocchella, A., Olivieri, G., 2019. Current bottlenecks and challenges of the microalgal biorefinery. Trends Biotechnol. 37 (3), 242-252.

Gnansounou, E., Raman, J.K., 2016. Life cycle assessment of algae biodiesel and its coproducts. Appl. Energy 161 (1), 300-308.

Gomes, N., Teixeira, J.A., Belo, I., 2012. Fed-batch versus batch cultures of Yarrowia lipolytica for $\gamma$-decalactone production from methyl ricinoleate. Biotechnol. Lett. 34 (4), 649-654.

Hansen, E.H., Møller, B.L., Kock, G.R., Bünner, C.M., Kristensen, C., Jensen, O.R., Okkels, F.T., Olsen, C.E., Motawia, M.S., Hansen, J., 2008. De novo biosynthesis of vanillin in fission Yeast (Schizosaccharomyces pombe) and Baker's yeast (Saccharomyces cerevisiae). Appl. Environ. Microbiol. 75 (9).

Indexmundi, 2019a. Fishmeal Monthly Price - US Dollars per Metric Ton.

Indexmundi, 2019b. Palm oil Monthly Price - US Dollars per Metric Ton.

Jin, M., Slininger, P.J., Dien, B.S., Waghmode, S., Moser, B.R., Orjuela, A., da Costa Sousa, L., Balan, V., 2015. Microbial lipid-based lignocellulosic biorefinery: feasibility and challenges. Trends Biotechnol. 33 (1), 43-54.

Karlsson, H., Ahlgren, S., Sandgren, M., Passoth, V., Wallberg, O., Hansson, P.-A., 2016. A systems analysis of biodiesel production from wheat straw using oleaginous yeast: process design, mass and energy balances. Biotechnol. Biofuels 229 (9).

Kern, J.D., Hise, A.M., Characklis, G.W., Gerlach, R., Viamajala, S., Gardner, R.D., 2017 Using life cycle assessment and techno-economic analysis in a real options framework to inform the design of algal biofuel production facilities. Bioresour. Technol. 225, $418-428$.

Kitcha, S., Cheirsilp, B., 2011. Screening of oleaginous yeasts and optimization for lipid production using crude glycerol as a carbon source. Energy Procedia 9, 274-282.

Koutinas, A.A., Chatzifragkou, A., Kopsahelis, N., Papanikolaou, S., Kookos, I.K., 2014 Design and techo-economic evaluation of microbial oil production as a renewable resource for biodiesel and oleochemical production. Fuel 116, 566-577.

Luo, L., van der Voet, E., Huppes, G., Udo de Haes, H.A., 2009. Allocation issues in LCA methodology: a case study of corn stover-based fuel ethanol. Int. J. Life Cycle Assess. 14 (6), 529-539.

Makri, A., Fakas, S., Aggelis, G., 2010. Metabolic activities of biotechnological interest in Yarrowia lipolytica grown on glycerol in repeated batch cultures. Bioresour. Technol. 101 (7), 2351-2358.

Manganaro, J.L., Lawal, A., Goodall, B., 2015. Techno-economics of microalgae production and conversion to refinery-ready oil with co-product credits. Biofuels Bioprod. Biorefin. 9, 760-777.

Martini, A.E.V., Miller, M.W., Martini, A., 1979. Amino acid composition of whole cells of different yeasts. J. Agric. Food. Chem. 27 (5), 982-984.

Matassa, S., Boon, N., Pikaar, I., Verstraete, W., 2016. Microbial protein: future sustainable food supply route with low environmental footprint. Microb. Biotechnol. 9 (5), $568-575$.

Michalik, B., Biel, W., Lubowicki, R., Jacyno, E., 2014. Chemical composition and biological value of proteins of the yeast Yarrowia lipolytica growing on industrial glycerol. Can. J. Anim. Sci. 94 (1), 99-104.

Mirończuk, A.M., Furgała, J., Rakicka, M., Rymowicz, W., 2013. Enhanced production of erythritol by Yarrowia lipolytica on glycerol in repeated batch cultures. J. Ind. Microbiol. Biotechnol, 41, 57-64.

Montazeri, M., Soh, L., Pérez-López, P., Zimmerman, J.B., Eckelman, M.J., 2016. Timedependent life cycle assessment of microalgal biorefinery co-products. Biofuels Bioprod. Biorefin. 10 (4), 409-421.

Øverland, M., Tauson, A.-H., Shearer, K., Skrede, A., 2010. Evaluation of methane-utilising bacteria products as feed ingredients for monogastric animals. Arch. Anim. Nutr. 64 (3), 171-189.

Panis, G., Carreon, J.R., 2016. Commercial astaxanthin production derived by green alga Haematococcus pluvialis: a microalgae process model and a techno-economic assessment all through production line. Algal Res. 18, 175-190.

Papanikolaou, S., Dimou, A., Fakas, S., Diamantopoulou, P., Philippoussis, A., GaliotouPanayotou, M., Aggelis, G., 2011. Biotechnological conversion of waste cooking olive oil into lipid-rich biomass using Aspergillus and Penicillium strains. J. Appl. Microbiol. 110 (5), 1138-1150.

Papanikolaou, S., Galiotou-Panayotou, M., Chevalot, I., Komaitis, M., Marc, I., Aggelis, G. 2006. Influence of glucose and saturated free-fatty acid mixtures on citric acid and lipid production by Yarrowia lipolytica, 52 (2), 134-142.

Papanikolaou, S., Kampisopoulou, E., Blanchard, F., Rondags, E., Gardeli, C., Koutinas, A.A., Chevalot, I., Aggeli, G., 2017. Production of secondary metabolites through glycerol fermentation under carbon-excess conditions by the yeasts Yarrowia lipolytica and Rhodosporidium toruloides. Eur. J. Lipid Sci. Technol. 119 (9), 1600507.

Parsons, S., Abeln, F., McManus, M.C., Chuck, C.J., 2018a. Techno-economic analysis (TEA) of microbial oil production from waste resources as part of a biorefinery concept: assessment at multiple scales under uncertainty. J. Chem. Technol. Biotechnol. 94 (3), 701-711.

Parsons, S., Allen, M., Abeln, F., McManus, M.C., Chuck, C.J., 2019. Sustainability and life cycle assessment (LCA) of macroalgae-derived single cell oils. J. Cleaner Prod. 232 (10), 1272-1281.

Parsons, S., Chuck, C.J., McManus, M.C., 2018b. Microbial lipids: progress in life cycle 
assessment (LCA) and future outlook of heterotrophic algae and yeast-derived oils. J. Cleaner Prod. (172), 661-672.

Passell, H., Dhaliwal, H., Reno, M., Amotz, A.B., Ivry, E., Gay, M., Czartoski, T., Laurin, L., Ayer, N., 2013. Algae biodiesel life cycle assessment using current commercial data. J. Environ. Manage. 129, 103-111.

Pehnelt, G., Vietze, C., 2013. Recalculating GHG emissions saving of palm oil biodiesel. Environ. Dev. Sustain. 15 (2), 429-479.

Pérez-López, P., González-García, S., Jeffryes, C., Agathos, S.N., McHugh, E., Walsh, D., Murray, P., Moane, S., Feijoo, G., Moreira, M.T., 2014a. Life cycle assessment of the production of the red antioxidant carotenoid astaxanthin by microalgae: from lab to pilot scale. J. Cleaner Prod. 64, 332-344.

Pérez-López, P., González-García, S., Ulloa, R.G., Sineiro, J., Feijoo, G., Moreira, M.T., 2014b. Life cycle assessment of the production of bioactive compounds from Tetraselmis suecica at pilot scale. J. Cleaner Prod. 64, 323-331.

Pérez-López, P., Montazeri, M., Feijoo, G., Moreira, M.T., Eckelman, M.J., 2018. Integrating uncertainties to the combined environmental and economic assessment of algal biorefineries: a Monte Carlo approach. Sci. Total Environ. 626, 762-775.

Ponnusamy, S., Reddy, H.K., Muppaneni, T., Downes, C.M., Deng, S., 2014. Life cycle assessment of biodiesel production from algal bio-crude oils extracted under subcritical water conditions. Bioresour. Technol. 170, 454-461.

PR Newswire, 2019. Algae Omega-3 Ingredients Market - Growth, Trends and Forecasts (2019 - 2024).

Quinn, J.C., Davis, R., 2015. The potentials and challenges of algae based biofuels: review of the techno-economic, life cycle, and resource assessment modeling. Bioresour. Technol. 184, 444-452.

Ratledge, C., 1989. Microbial Lipids, vol. 2. In: Ratledge, C., Wilkinson, S.G. (Eds.), Academic Press, pp 567-668.

Resurreccion, E.P., Colosi, L.M., White, M.A., Clarens, A.F., 2012. Comparison od algae cultivation methods for bioenergy production using combined life cycle assessment and life cycle costing approach. Bioresour. Technol. 7, 298-306.

Richardson, J.W., Johnson, M.D., Outlaw, J.L., 2012. Economic comparison of open pond raceways to photo bio-reactors for profitable production of algae for transportation fuels in the Southwest. Algal Res. 1 (1), 93-100.

Ritala, A., Häkkinen, S.T., Toivari, M., Wiebe, M.G., 2017. Single cell protein-state-of the-art, industrial landscape and patents 2001-2016. Front. Microbiol. 8 (2009).
Rodrigues, A., Bordado, J.B., dos Santos, R.G., 2017. Upgrading the glycerol from biodiesel production as a source of energy carriers and chemicals-a technological review for three chemical pathways. Energies 10 (11).

Sandin, G., Røyne, F., Berlin, J., Peters, G.M., Svanström, M., 2015. Allocation in LCAs of biorefinery products: implications for results and decision-making. J. Cleaner Prod. 93, 213-221.

Sauer, M., Porro, D., Mattanovich, D., Branduardi, P., 2008. Microbial production of organic acids: expanding the markets. Trends Biotechnol. 26 (2), 100-108.

Seafish, 2016. Fishmeal and Fish Oil Facts and Figures. Sea Fish Industry Authority.

Soh, L., Montazeri, M., Haznedaroglu, B.Z., Kelly, C., Peccia, C., Eckelman, M.J., Zimmerman, J.B., 2014. Evaluating microalgal integrated biorefinery schemes: empirical controlled growth studies and life cycle assessment. Bioresour. Technol. 151, 19-27.

Soratana, K., William, J.B., Landis, A.E., 2014. Effects of co-products on the life cycle impacts of microalgal biodiesel. Bioresour. Technol. 159, 157-166.

Souza, K.S., Schwan, R.F., Dias, D.R., 2014. Lipid and citric acid production by wild yeasts grown in glycerol. J. Microbiol. Biotechnol. 24 (4), 497-506.

Spolaore, P., Joannis-Cassan, C., Duran, E., A, I., 2006. Commercial applications of microalgae. J. Biosci. Bioeng. 102 (2), 87-96.

Thomassen, G., Vila, U.E., Van Dael, M., Lemmens, B., Van Passel, S., 2016. A technoeconomic assessment of an algal-based biorefinery. Clean Technol. Environ. Policy 18 (6), 1849-1862.

United States Environmental Protection Agency, 2019. Renewable Fuel Standard Program: Standards for 2019 and Biomass-Based Diesel Volume for 2020, Vol. EPAHQ-OAR-2018-0167 FRL-9987-66-OAR.

van der Voort, M., Spruijt, J., Potters, J., de Wolf, P., Elissen, H., 2017. Socio-economic Assessment of Algae-based PUFA Production. Wageningen Research.

Vlysidis, A., Binns, M., Webb, C., Theodoropoulos, C., 2011. A techno-economic analysis of biodiesel biorefineries: assessment of integrated designs for the co-production of fuels and chemicals. Energy 36, 4671-4683.

Wijffels, R.H., Barbosa, M.J., 2010. An outlook on microalgal biofuels. Science 329 (5993), 796-799.

Xiang, X., Ozkan, A., Chiriboga, O., Kelly, C., 2017. Techno-economic analysis of glucosamine and lipid production from marine diatom Cyclotella sp. Bioresour. Technol. 244 (2), 1480-1488. 